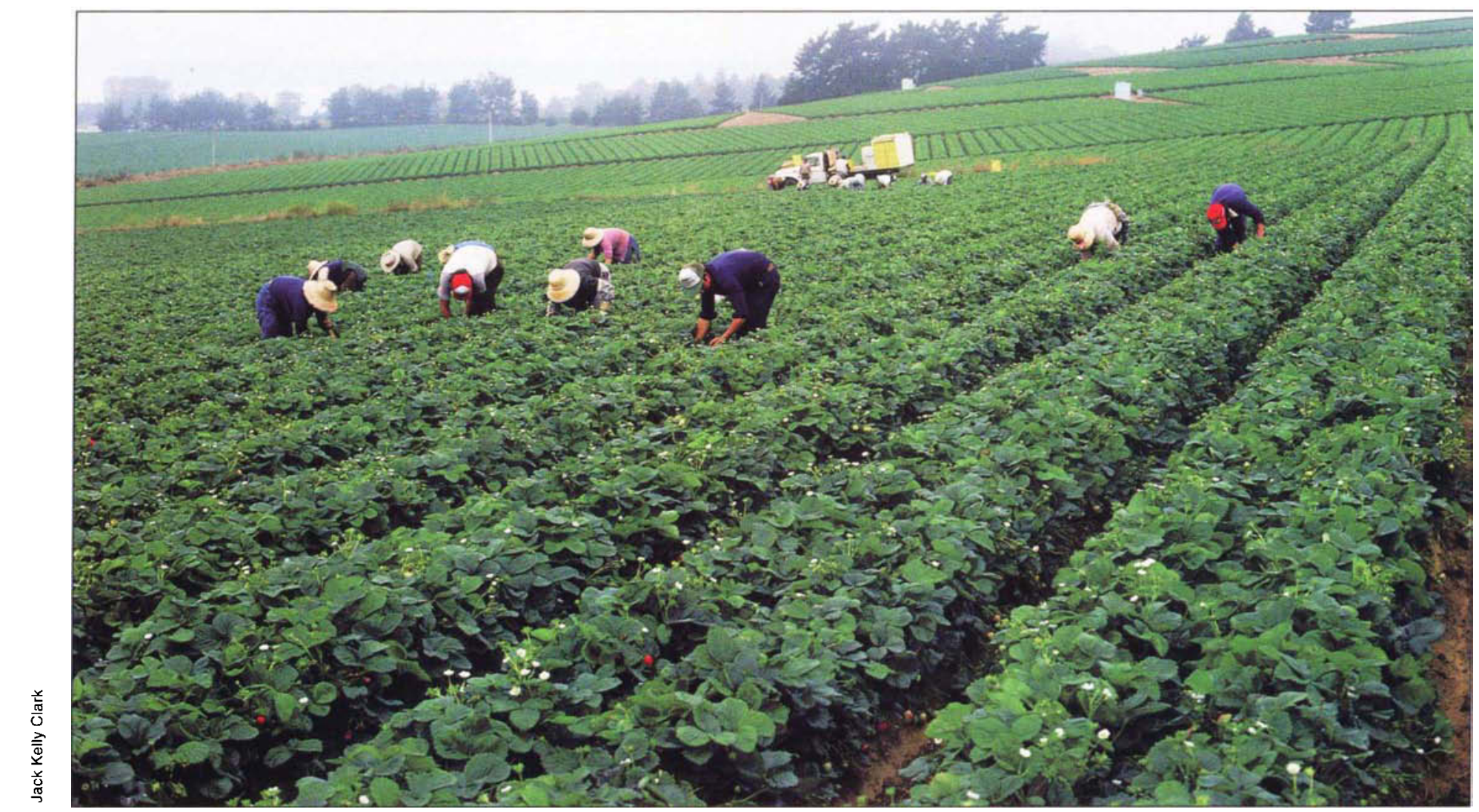

\title{
Township limits on 1,3-D will impact adjustment to methyl bromide phase-out
}

\author{
Janet Carpenter $\square$ Lori Lynch 」 Tom Trout
}

$\mathrm{M}$ ethyl bromide, an agricultural and structural fumigant, is widely used in California to control crop diseases, nematodes and weeds. In 1992, it was identified as a class I ozone depletor under the Montreal Protocol (1992), an international treaty to reduce ozone-depleting substances worldwide. This announcement resulted in regulation of methyl bromide in the United States under the Clean Air Act, which requires the phase-out of a substance within 7 years of the determination that it is a class I ozone depletor. All production and importation of methyl bromide was to be banned by Jan. 1, 2001. However, in 1998, the U.S. Congress amended the Clean Air Act to harmonize the U.S. phase-out with the international schedule under the Montreal Protocol, with reductions of $25 \%$ by $1999,50 \%$ by $2001,70 \%$ by 2003 and $100 \%$ by 2005 .
Methyl bromide is also subject to regulations specific to California. Since 1992, the use of methyl bromide has been restricted through discretionary controls set at the county level. The California Department of Pesticide Regulation (CDPR) recently finalized regulations to codify many countylevel restrictions into state law. In addition, the new state-level regulations increase requirements for notifying neighbors prior to methyl bromide fumigation and impose more restrictive buffer requirements around application sites. These new state regulations are limiting the use of methyl bromide in some areas, even before the phaseout under the Montreal Protocol.

Cost-effective alternatives to methyl bromide are sought for crops such as strawberries, perennials, watermelons, tomatoes, lettuce and nursery crops. Researchers have identified 


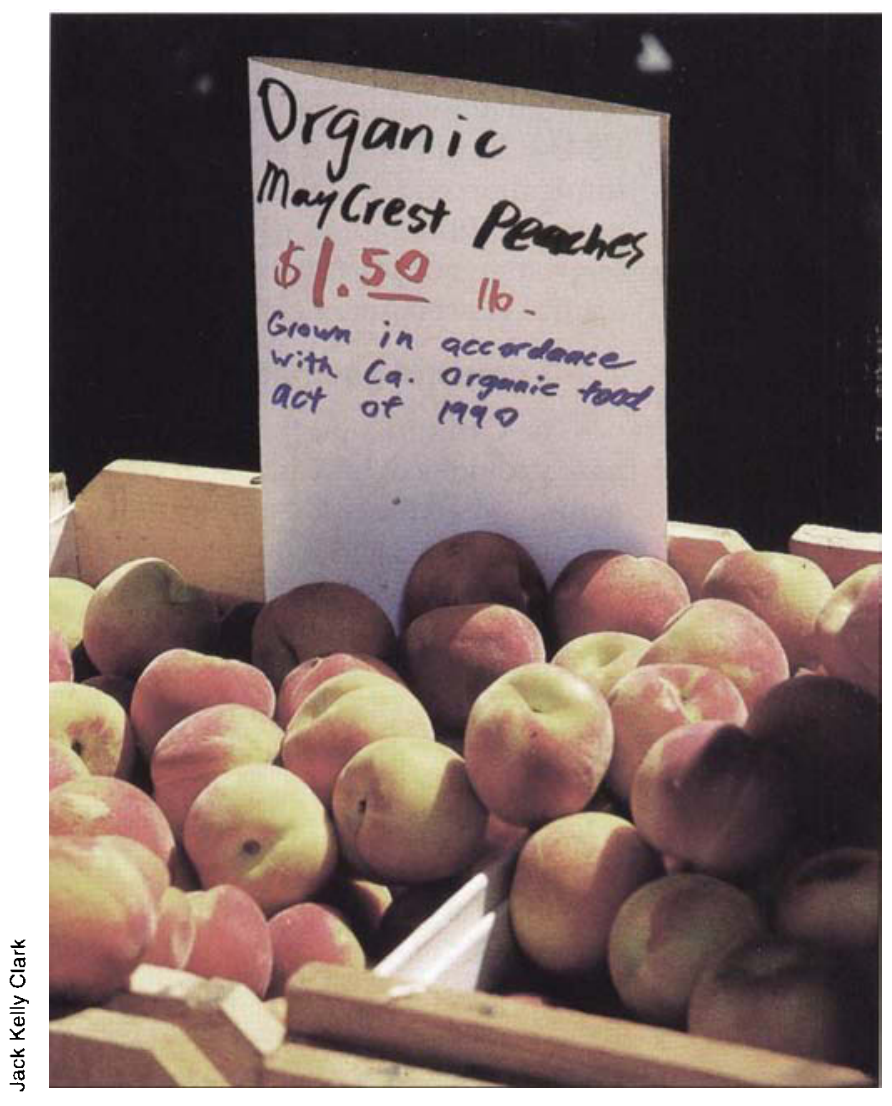

4 Strawberries are the largest single user of methyl bromide in California, with more than $90 \%$ of acreage treated. After methyl bromide is phased out in 2005, the authors expect many growers to choose alternative fumigants such as 1,3-D and chloropicrin, metam sodium or dazomet.

\section{$\Delta$ The authors estimate that at least 173 acres of peaches would be affected by township limits on 1,3-D.}

\section{1,3-dichloropropene (1,3-D; trade} name Telone), either alone or in combination with other chemicals such as chloropicrin, as the most effective alternative to fumigation with methyl bromide in terms of the lowest per-unit cost (Carpenter et al. 2000). However, researchers and policy-makers express concern about the wide-scale availability of 1,3-D as a replacement for methyl bromide, due to restrictions on its use.

California suspended the use of 1,3-D in April 1990 after monitoring detected levels above air quality standards in Merced County. In December 1994, the state reinstated its use with several restrictions. Current restrictions limit total 1,3-D use within 36square-mile areas, known as townships. Additional practices are also encouraged to minimize levels of 1,3-D in ambient air. These restrictions are intended to address the air quality concerns that led to its cancellation.

\section{1,3-D use in California}

Agricultural producers applied over 3 million pounds of $1,3-\mathrm{D}$ in California in 1999 on a wide variety of crops (fig. 1) (CDPR 1999a).

Applied as a soil fumigant, 1,3-D acts primarily as a nematicide but also controls viruses, bacteria, soil insects and fungi. Carrots accounted for nearly $30 \%$ of this use. Tomatoes were the next largest single crop use. Perennial crops, including grapes, almonds and walnuts also account for a large portion of 1,3-D use. For some of these crops, growers might choose to use either methyl bromide or 1,3-D, depending on pest pressure, soil type and cost. For example, grapes, almonds and walnuts are also among major methyl bromide-using crops.

State guidelines. In 1994, CDPR issued suggested permit guidelines to county agricultural commissioners for the use of 1,3-D. These guidelines have been modified several times with the latest ones issued in 1999. Current restrictions include a limit on the total amount of 1,3-D that may be applied within each township, depending on the depth and timing of applications (CDPR 1999b). A total of 90,250 pounds of 1,3-D per township is allowed if all applications are made to a depth greater than 18 inches between February and November. The limit is reduced if applications are made at shallow depths of less than 18 inches or during December or January. The lower limits are calculated by counting each pound applied at a shallow depth during February through November as 1.9 pounds. Similarly, the amount of 1,3-D used is weighted more heavily for applications during December or January. These practices are

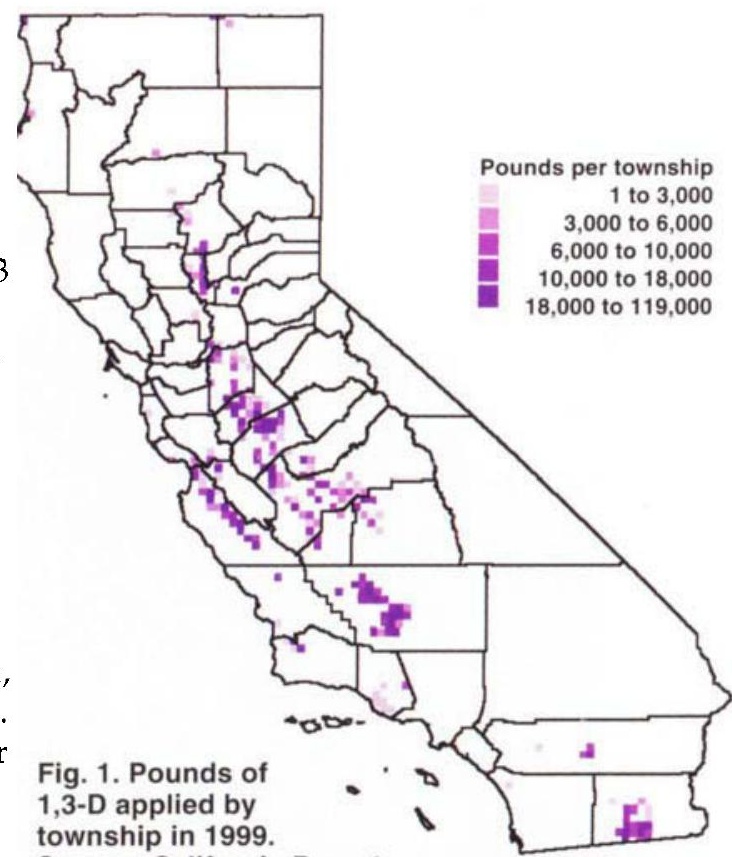

township in 1999.

Source: California Depart-

ment of Pesticide Regulation.

intended to minimize levels of 1,3-D in ambient air. If all applications are made at a shallow depth between February and November, the limit is 47,500 pounds.

In addition to the township caps, growers must maintain a buffer of 300 feet around occupied structures, which may be greater than that required for methyl bromide-treated acres. Growers must also meet soil-moisture requirements that may reduce the efficacy of 1,3-D. The liquid 1,3-D rapidly volatilizes into a gas when injected into the soil. The amount of soil moisture influences how well 1,3-D moves through the soil. If soil moisture levels are too high, efficacy can be reduced (Carpenter et al. 2000). Also, the maxi-

TABLE 1. Application rate assumptions used in 1,3-D township restriction analysis

\begin{tabular}{lcc}
\hline \hline Crop & 1,3-D rate & Application depth \\
\hline & Ib/acre & \\
Almonds & 332 & $>18^{\prime \prime}$ \\
Carrots & 97.5 & $>18^{\prime \prime}$ \\
Grapes & 332 & $>18^{\prime \prime}$ \\
Lettuce & 76 & $<18^{\prime \prime}$ \\
Nursery & 235 & $<18^{\prime \prime}$ \\
Peaches & 332 & $>18^{\prime \prime}$ \\
Peppers & 76 & $<18^{\prime \prime}$ \\
Strawberries & 235 & $<18^{\prime \prime}$ \\
Sweet potatoes & 190 & $>18^{\prime \prime}$ \\
Tomatoes & 76 & $<18^{\prime \prime}$ \\
Walnuts & 332 & $>18^{\prime \prime}$ \\
Watermelons & 114 & $<18^{\prime \prime}$ \\
\hline
\end{tabular}




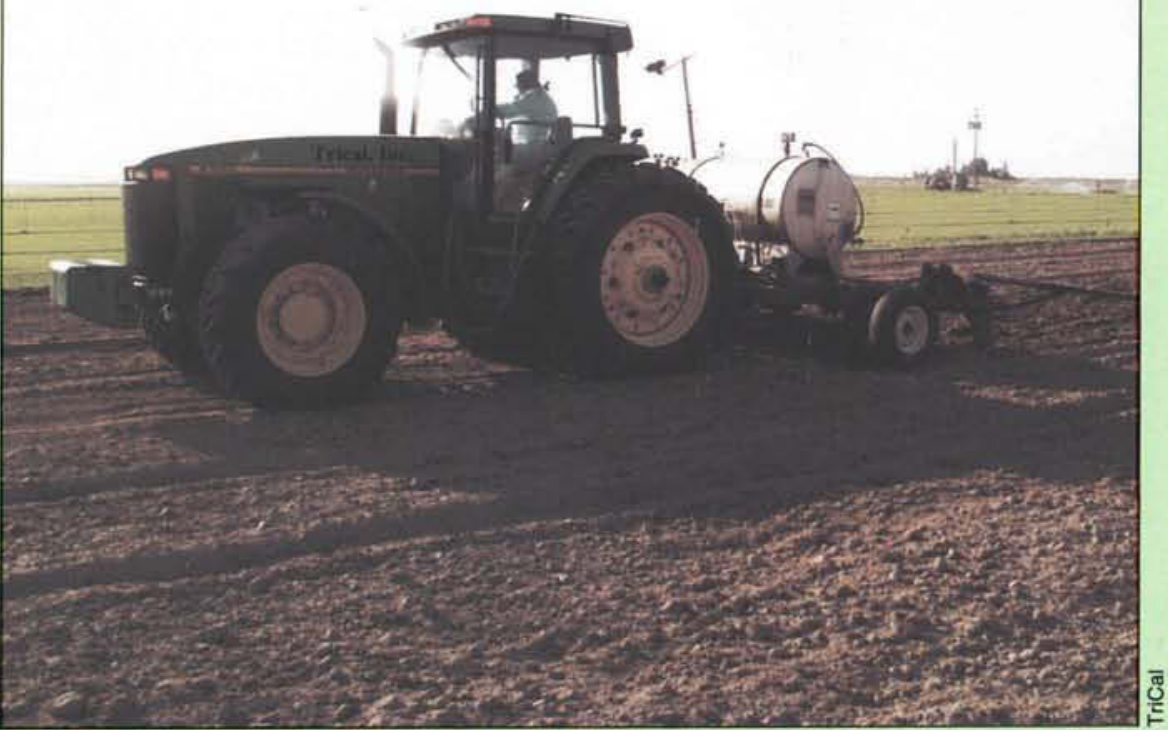

$1,3-D$ is typically applied by custom applicators using a rig to inject the liquid into the soil, where it volatilizes into a gas.

\section{1,3-D uses and restrictions}

According to the U.S. Environmental Protection Agency (1998), 1,3-dichloropropene $(1,3-\mathrm{D})$ is registered for use on soils to be planted with all food and feed crops. It can be applied only by certified applicators, and no homeowner uses are allowed.

$1,3-\mathrm{D}$ is highly volatile, and is mobile in soils; its persistence appears to be inversely related to temperature. 1,3-D is not believed to be a risk to birds or nontarget insects, but could be risky to aquatic invertebrates and fish, according to EPA.

$1,3-\mathrm{D}$ is classified as a category "B2" or "possible human carcinogen," by both oral and inhalation routes of exposure. In California, it is included on the Proposition 65 list of chemicals known to the state to cause cancer.

In 1986, EPA placed 1,3-D under special review, based on cancer concerns for workers, possible groundwater contamination and residues on crops grown in treated soils. In 1991, EPA's review was expanded to include inhalation exposures to residents who live near treated fields.
In 1992 and 1996, Dow AgroSciences requested new label changes to reduce levels of pesticide volatilization, including shut-off valves, closed loading, soil sealing, a 300-foot no treatment buffer from occupied structures, improved product stewardship, and reduced application rates. Additional restrictions and regulations apply in California (see p. 13).

In 1998, EPA published its reregistration eligibility decision (RED) for 1,3-D. "The agency has concluded that when labeled and used as specified, [1,3-D] will not cause unreasonable risks to human health or the environment," EPA wrote.

As a condition of reregistration, Dow AgroSciences agreed to conduct tap-water monitoring studies, and develop additional data on 1,3-D degradates, impacts on estuarine environments, and possible surface-water contamination. -Editor

U.S. Environmental Protection Agency. 1998. Reregistration Eligibility Decision: 1,3Dichloropropene. Office of Prevention, Pesticides and Toxic Substances. EPA 738-R-98016. www.epa.gov/oppsrrd1/REDs/0328red.pdf mum allowable application rate for 1,3-D is 24 gallons per acre for tarped fumigation and 35 gallons for untarped fumigation, which for some crops may not provide reliable pest control (Carpenter et al. 2000).

\section{1,3-D demand estimates}

The California pesticide use database provides detailed, spatial information on all pesticide applications, which allows calculation of pesticide use by township (CDPR 1999a). We use 1999 pesticide use data, the most recent available, to first compute current use of 1,3-D and methyl bromide in each township. We then estimate demand for 1,3-D after a methyl bromide phase-out for all methyl bromideusing crops for which researchers indicate that $1,3-\mathrm{D}$ is the preferred alternative. Information was collected through two regional meetings, published research and numerous interviews with scientists, growers and policy-makers as to the relevant and most likely alternatives to methyl bromide following the ban (Carpenter et al. 2000). All current uses of 1,3-D are included in the calculation.

Growers who have depended on methyl bromide were assumed to switch to 1,3-D at application rates and depths appropriate to the practices specific to each crop (table 1). These assumptions are based on the opinion of a representative of TriCal, one of six companies authorized to distribute 1,3-D in California (personal communication, Kirk Fowler, TriCal general manager). While application dates are included in California's pesticide use database, they are not included in this analysis because growers can adjust treatment dates between February and November. Between $5 \%$ and $18 \%$ of 1,3-D applications are made during December and January. The impact of buffer zones required for 1,3-D, which may be larger than those required for methyl bromide, is also not considered due to the site-specific nature of those restrictions and the lack of information about the location of structures in relationship to treated fields. Inclusion of these variables would likely further limit the allowable 1,3-D treatment area. 


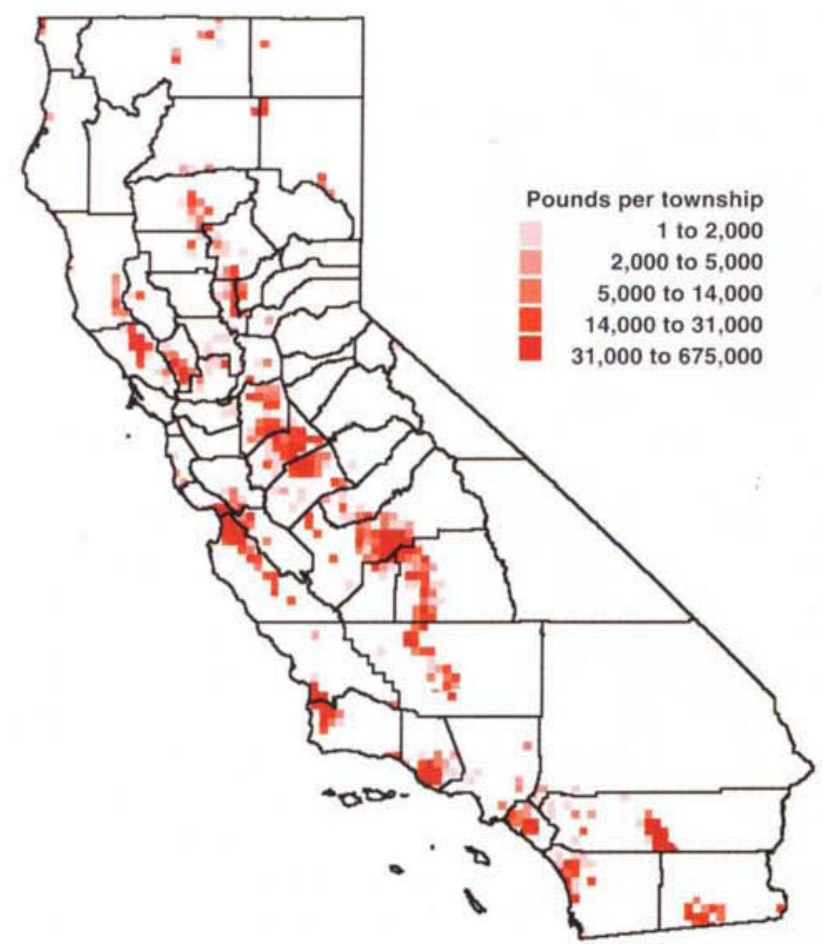

Fig. 2. Pounds of methyl bromide applied by township in 1999. Source: California Department of Pesticide Regulation.

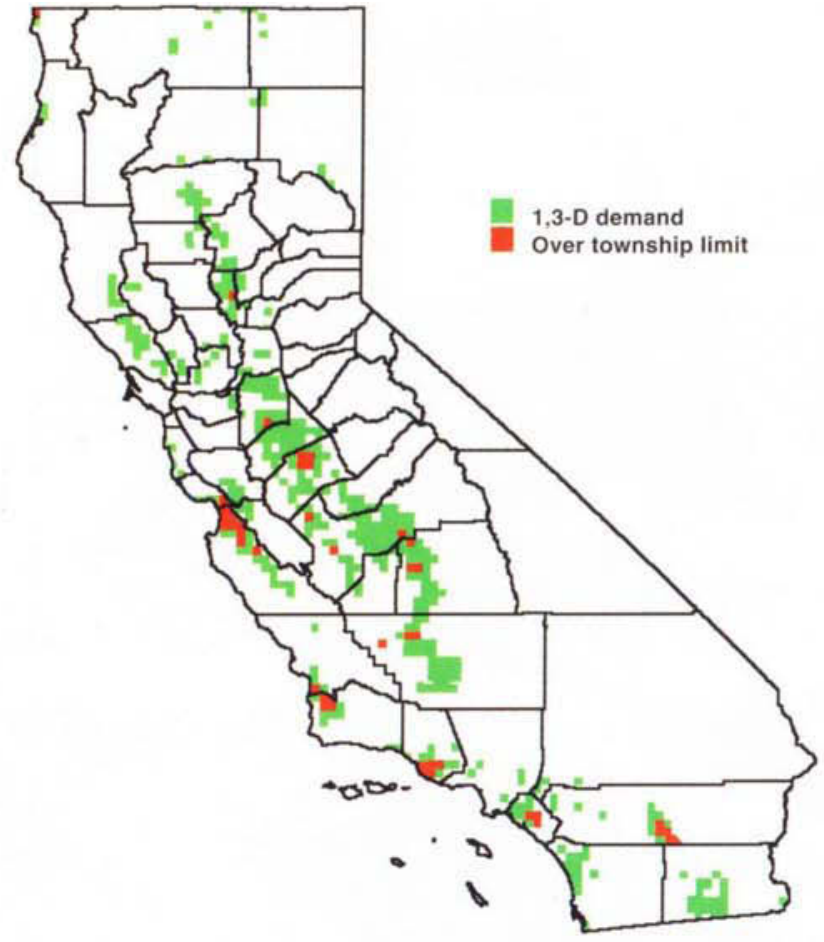

Fig. 3. Townships in which 1,3-D demand is expected to exceed regulatory limits.
Researchers identified the crops that are likely to use 1,3-D after the methyl bromide phase-out as strawberries, perennials, sweet potatoes, watermelons, peppers, tomatoes, carrots and lettuce, along with crops grown in nurseries (Carpenter et al. 2000; Methyl Bromide Alternatives 2000). Acreage in these crops represents over $90 \%$ of areas treated with methyl bromide. The remaining area that is treated with methyl bromide consists of other crops for which the likely alternative is not known.

Strawberries. Strawberries account for the single largest use of methyl bromide in California. Between 1997 and 1999 , over $95 \%$ of the state's strawberry acreage was treated with methyl bromide. While a $50 \%$ methyl bromide phase-out went into effect in 2001, pesticide use data for 2000 and 2001 are not yet available. Areas that are not treated are either in organic production or are plantings in their second year of production. A great deal of research has been conducted to identify effective alternatives to methyl bromide for California strawberry growers (Methyl Bromide Alternatives 2000).
Researchers believe that after a methyl bromide phase-out, strawberry growers are likely to choose an alternative fumigant such as $1,3-\mathrm{D}$, chloropicrin, metam sodium or dazomet, most likely used in combination (Shaw and Larson 1999).

In Carpenter et al. (2000), we reviewed research into numerous chemical and nonchemical methyl bromide alternatives for strawberries (including solarization, organic cultivation and others), and determined that the no-fumigation option results in a $40 \%$ to $60 \%$ yield decrease. Although $1,3-\mathrm{D}$ is not considered as cost-effective as methyl bromide, we believe growers will prefer it to not fumigating at all. Nonetheless, it remains unclear whether 1,3-D is an effective component of an alternative chemical treatment. In light of this uncertainly, we have analyzed two scenarios, assuming growers will or will not switch to 1,3-D.

Data adjustments. The 1999 pesticide use data were adjusted in order to address issues in the reporting of methyl bromide use. First, treated acreage may be overstated for methyl bromide applications in perennial crops due to reporting of spot treatments on less than 1 acre as full-acre treatments. Therefore, all records with application rates of less than 50 pounds per acre were deleted. Second, an adjustment was made for unspecified methyl bromide use. More than 2 million pounds of methyl bromide use is not reported as targeting any particular crop, accounting for more than 8,000 treated acres equal to $13 \%$ of areas treated with methyl bromide. Agricultural commissioners in the counties with a large amount of unspecified use were surveyed for further information on which crops were being fumigated. Unspecified use in Orange County $(333,282$ pounds) was assumed to be strawberry acreage. The breakdown of unspecified uses in Fresno, Madera and Tulare counties, which together account for more than 1.5 million pounds of unspecified methyl bromide use, is attributed to perennial crops. All 56,375 pounds of unspecified use in Siskiyou County was assumed to be for strawberry nurseries. Unspecified use in other counties is not included. Finally, 315 records of methyl bromide and 1,3-D 


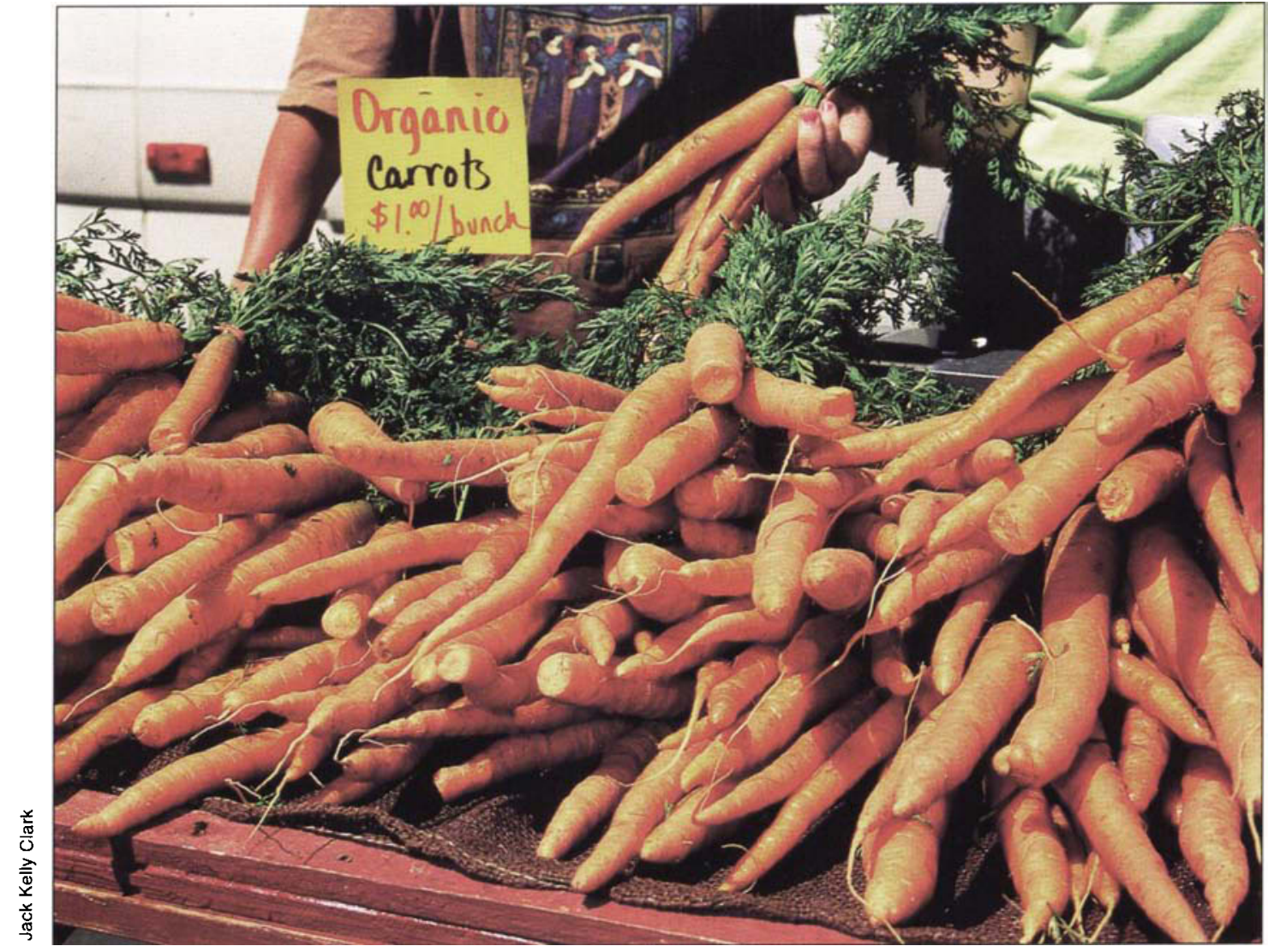

Carrots are among the crops with the highest anticipated demand for 1,3-D after the methyl bromide phase-out.

TABLE 2. Estimated 1,3-D demand after methyl bromide phase-out*

\begin{tabular}{lcc}
\hline \hline County & $\begin{array}{c}\text { With } \\
\text { strawberries }\end{array}$ & $\begin{array}{c}\text { Without } \\
\text { strawberries }\end{array}$ \\
\hline Monterey & $\mathrm{lb}$ & $\mathrm{Ib}$ \\
Ventura & $2,599,451$ & 747,904 \\
Fresno & $2,152,026$ & 188,289 \\
Merced & $1,272,901$ & $1,267,907$ \\
Kern & $1,193,100$ & $1,175,863$ \\
Santa Barbara & $1,162,733$ & $1,161,088$ \\
Tulare & $1,086,176$ & 199,920 \\
Stanislaus & 762,886 & 762,886 \\
Santa Cruz & 698,719 & 691,906 \\
Orange & 620,688 & 74,313 \\
Riverside & 500,285 & 54,824 \\
San Joaquin & 400,625 & 398,111 \\
Sonoma & 389,400 & 386,580 \\
Imperial & 371,950 & 371,198 \\
Sutter & 356,378 & 356,378 \\
San Diego & 328,361 & 327,186 \\
San Luis Obispo & 211,062 & 175,083 \\
Butte & 194,684 & 64,048 \\
Madera & 183,668 & 183,668 \\
Lassen & 145,107 & 143,908 \\
State Totalt & 125,340 & 0 \\
\hline Based & $15,632,630$ & $9,443,428$ \\
\hline
\end{tabular}

"Based on 1999 California pesticide use database. †Sum does not equal total. Not all counties shown. applications were identified as duplicates and deleted.

\section{Impact of township restrictions}

Binding township restrictions limit the number of acres that may be treated with 1,3-D in some areas. In 1999, two townships in Monterey County were over the 90,250-pound township limit. These totals are not adjusted to account for shallow application depth, which would lower the allowable amount of 1,3-D in each township to below 90,250 pounds. Eight other townships used more than 47,500 pounds of $1,3-\mathrm{D}$, which is the lower limit if all applications are made at a shallow depth from February to November. Three of these townships are in Kern County, where carrot acreage is concentrated. Fresno, Merced and Stanislaus counties each had townships exceeding 47,500 pounds of 1,3-D applications in 1999.

California growers applied a total of 14 million pounds of methyl bromide in 1999 on a wide variety of crops, including strawberries, tomatoes, flowers, perennials and nursery crops (fig. 2). If all these growers switch to 1,3-D after the methyl bromide phaseout, the restrictions are expected to limit 1,3-D use in even more townships.

\section{With and without strawberries}

Demand for 1,3-D is estimated to increase from 3 million pounds in 1999 to nearly 16 million pounds if strawberry growers use 1,3-D. However, under current restrictions, use would be limited to 10 million pounds, which is $64 \%$ of total demand (table 2).

Monterey County is expected to have the highest demand for 1,3-D, primarily by strawberry growers, followed by Ventura County, also a major strawberryproducing county. Several of the other counties with high levels of demand are in the Central Valley: Fresno, Merced and Kern.

Demand for 1,3-D is estimated to increase to 9.4 million pounds if strawberry growers do not use 1,3-D (table 2). However, under current restrictions, use will be limited to 8.3 million pounds ( $88 \%$ of total demand). The level of demand is much lower in Monterey, Ventura, Santa Barbara, Santa Cruz and Orange counties if strawberry growers choose to use an alternative other than 1,3-D.

We predict that the restrictions will be binding in 47 townships (table 3; fig. 3). With the largest acreage in strawberry production, Monterey County has the most townships (10) with demand in excess of current limits. If strawberries are not included, the restrictions will be binding in 23 townships. Merced County has the highest number of townships (4) with 1,3-D demand over the limit, for treatment of sweet potatoes, almonds, peaches and nursery crops.

\section{Distribution issues}

The use of 1,3-D must be distributed by some mechanism in areas 
where the restrictions will be binding. Assuming the available 1,3-D is distributed by crop in proportion to its demand within each township, an estimate of which crops are most affected by the restrictions may be obtained. Along with nurseries, the crops expected to be most affected are strawberries, sweet potatoes, perennials, peppers, broccoli, and processing tomatoes (table 4).

For many crops, whether or not strawberry growers choose to use 1,3-D has little impact on how the restrictions will affect the amount of acreage that they are allowed to treat, since these crops are generally grown in areas where strawberries are not grown. This is the case for crops such as perennials, sweet potatoes, carrots and watermelons grown primarily in California's interior valleys. However, some crops would be in direct competition with strawberries for allotted 1,3-D use. These crops are grown in proximity to strawberries, including broccoli, Brussels sprouts, lettuce, peppers and tomatoes.

The pest control industry is charged with allocating limited 1,3-D use, reporting treatments made to county commissioners. To date, no entity has determined which crops or growers will be able to use 1,3-D and which will not. Several distribution mechanisms could be used to allocate pesticide use: first come, first served; quotas by crop, based on current or historical use; marketable permits; or a system based on the potential exposure of nearby populated areas. Currently, the use of 1,3-D is distributed on a first come, first served basis, as growers file notices of intent with the county agricultural commissioner just prior to treatment. Different methods will impact the distribution of benefits and costs under current regulations. Allowing the pest control industry to allocate distribution of limited 1,3-D use may not maximize society's welfare and may result in larger losses for the agricultural community after the phase-out of methyl bromide.

\section{Qualifications of analysis}

This analysis assumes that the production of crops will not geographi- cally relocate following the phase-out due to restrictions on 1,3-D use. Yet some growers may be able to shift crop production to another township where the limits are not binding. Assuming growers are planting in the most profitable areas for both soil conditions and climate, shifting to another township may decrease profits. In other cases, production cannot shift in the short run, either because growers own the land they farm, the restrictions in nearby townships are already binding or no other region supplies the needed growing conditions. Some growers are likely to adapt to the re- strictions by switching to crops that may be grown profitably without the use of 1,3-D.

In addition, new application methods, which decrease 1,3-D emissions, may allow the easing of the restrictions in California. Application of 1,3-D through drip irrigation systems, for instance, may reduce emissions from treated fields and allow larger areas to be treated. An emulsified version of Telone C-35 (1,3-D plus chloropicrin) recently received a full federal registration. Methods to reduce emissions during 1,3-D application for perennial crops are also being investi-
TABLE 3. Counties where 1,3-D township restrictions are expected to be binding*

\begin{tabular}{lrrrr}
\hline \hline & \multicolumn{2}{c}{ With strawberries } & & Without strawberries \\
\cline { 2 - 4 } County & $\begin{array}{c}\text { Number of townships } \\
\text { over limit }\end{array}$ & $\begin{array}{c}\text { Pounds of 1,3-D } \\
\text { over limitt }\end{array}$ & $\begin{array}{c}\text { Number of townships } \\
\text { over limit }\end{array}$ & $\begin{array}{c}\text { Pounds of 1,3-D } \\
\text { over limit }\end{array}$ \\
\hline Del Norte & 1 & 18,928 & 1 & 18,928 \\
Fresno & 3 & 113,297 & 3 & 113,297 \\
Kern & 3 & 408,242 & 3 & 407,349 \\
Merced & 4 & 464,758 & 4 & 442,589 \\
Monterey & 10 & $2,945,056$ & 3 & 166,038 \\
Orange & 3 & 492,163 & 0 & 0 \\
Riverside & 3 & 97,793 & 3 & 97,793 \\
San Joaquin & 1 & 56,731 & 1 & 56,731 \\
San Luis Obispo & 1 & 6,961 & 0 & 0 \\
Santa Barbara & 4 & $1,332,752$ & 0 & 0 \\
Santa Cruz & 4 & 702,404 & 0 & 0 \\
Sutter & 1 & 86,163 & 1 & 86,163 \\
Tulare & 3 & 90,087 & 3 & 90,087 \\
Ventura & 6 & $3,352,243$ & 1 & 20,721 \\
State total & 47 & $10,166,617$ & 23 & $1,499,697$
\end{tabular}

Based on 1999 California pesticide use database.

†Adjusted pounds where pounds of 1,3-D applied to a depth of less than 18 inches is counted as 1.9 pounds.

TABLE 4. Estimated acreage over township limit after methyl bromide phase-out

\begin{tabular}{lrrr}
\hline \hline Crop & $\begin{array}{c}\text { Acres over limit } \\
\text { with strawberries }\end{array}$ & $\begin{array}{c}\text { Acres over limit } \\
\text { without strawberries }\end{array}$ & $\begin{array}{c}\text { Total acres with } \\
\text { 1,3-D demand }\end{array}$ \\
\hline Almonds & 230 & 226 & 2,159 \\
Broccoli & 924 & 626 & 1,600 \\
Brussels sprouts & 207 & 0 & 357 \\
Carrots & 296 & 286 & 8,824 \\
Grapes & 200 & 152 & 1,205 \\
Lettuce & 157 & 41 & 1,435 \\
Nurseries & 2,077 & 1,274 & 6,502 \\
Peaches & 173 & 173 & 1,401 \\
Peppers & 994 & 324 & 3,555 \\
Soil application & 460 & 460 & 5,867 \\
Strawberries & 18,023 & 0 & $26,334 \dagger$ \\
Sweet potatoes & 1,787 & 1,741 & 4,133 \\
Tomatoes & 772 & 471 & 6,625 \\
Watermelons & 187 & 186 & 2,001 \\
State totalf & 26,879 & 6,266 & 83,340 \\
\hline
\end{tabular}

"Reported unspecified as to crop. The areas over the township limits are located primarily in Fresno and Tulare counties and are assumed to be perennial crops.

†Assuming strawberry growers choose to use 1,3-D. Two acres of strawberries were treated with 1,3-D in 1999.

†Sum does not equal state total. Not all crops shown. 


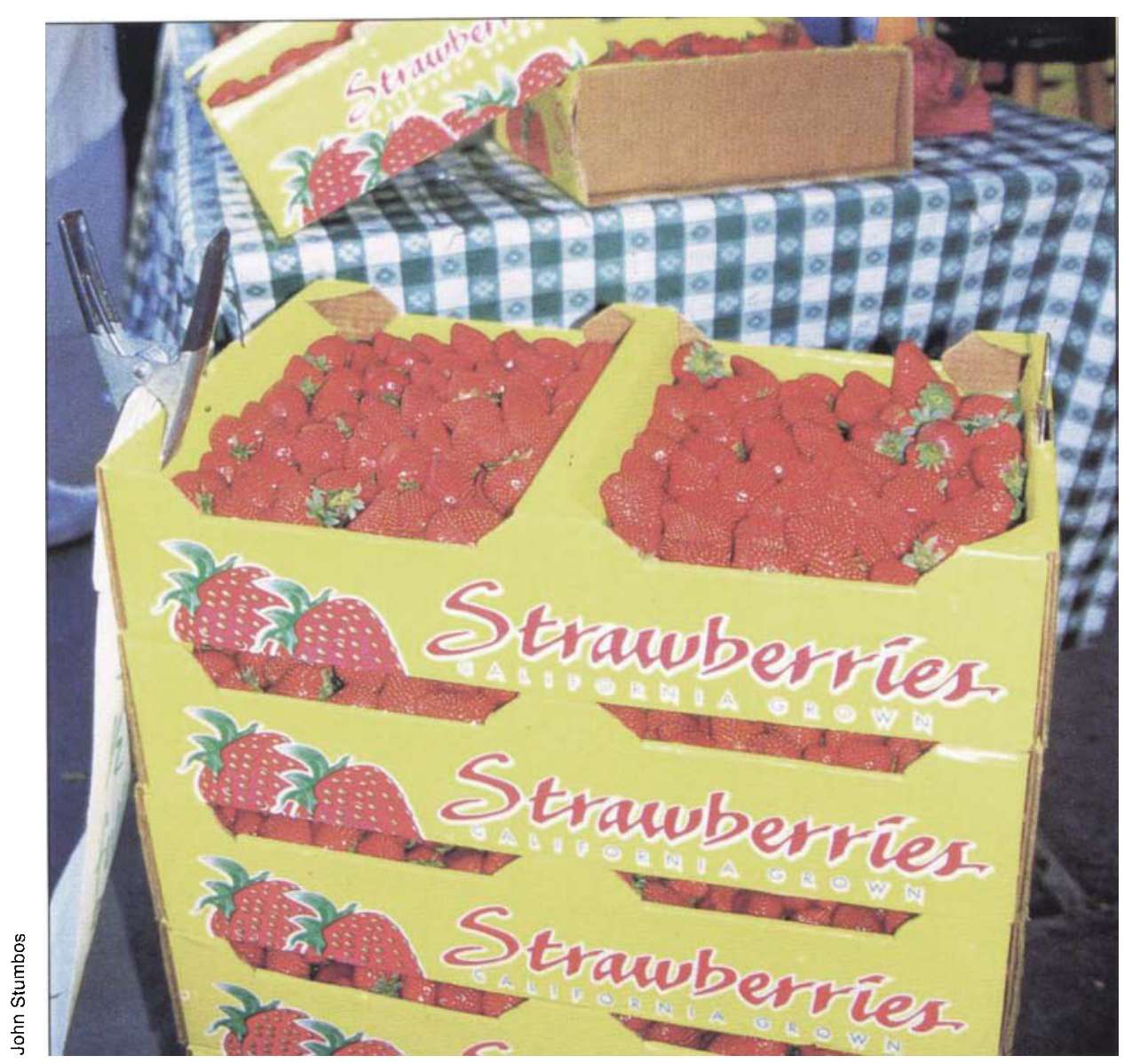

gated. To the extent that current restrictions may be eased through the use of new application technologies, the impacts calculated here will overestimate how binding the restrictions will be. However, it is not yet known whether these methods will reduce emissions (personal communication, Ron Oshima, CDPR, Assistant Director of Scientific Affairs)

Finally, this analysis includes only $90 \%$ of current methyl bromidetreated areas. To the extent that any of the remaining $10 \%$ of methyl bromide-treated areas switch to 1,3-D after the phase-out, our analysis underestimates the impact of township restrictions.

\section{Alternative strategies needed}

The phase-out of methyl bromide is underway, requiring a $50 \%$ reduction from 1991 levels for 2001 calendar year. California is also in the process of implementing new regulations on methyl bromide to restrict its use in some areas for air quality concerns. As methyl bromide applications are re- stricted, policy analysts expect growers to switch to 1,3-D. The results of this analysis demonstrate the impact that limits on 1,3-D use in California will have after the phase-out of methyl bromide under current restrictions and application methods. Our findings indicate that areas where strawberries and perennial crops are grown will be most affected. The efficacy of 1,3-D applications with emissions-reducing techniques such as drip application and specialized tarps may allow larger areas to be treated than estimated here. Estimates of which specific crops will be affected depend on assumptions about the manner in which the 1,3-D use will be distributed, the possibility of relocating crop production and the availability of application methods to reduce emissions.

These results may also be used to guide research efforts into promising alternatives to both methyl bromide tion techniques, new pesticides, herbicides and nonchemical pest control methods. Alternative pest control and $1,3-\mathrm{D}$, such as pesticide applica-
A $50 \%$ reduction in methyl bromide went into effect on Jan. 1, 2001, based on 1991 usage levels. A wide range of alternatives will be needed for effective pest control in strawberries and other crops.

strategies must be developed and tested if 1,3-D cannot be applied to all acreage. Research to identify and develop alternatives to methyl bromide has included several alternatives, $1,3-\mathrm{D}$ among them. While $1,3-\mathrm{D}$ is considered the most effective alternative, our results underscore the importance of developing a wider range of alternative practices.

J. Carpenter is Research Associate, National Center for Food and Agricultural Policy (NCFAP); L. Lynch is Assistant Professor, Agricultural and Resource Economics, University of Maryland, College Park; and T. Trout is Agricultural Engineer, USDA Agricultural Research Service. Lynch studied methyl bromiderelated issues as part of doctoral research at UC Berkeley. This study evolved from the study funded by the USDA Economic Research Service, "The Economic Impact of the Scheduled Phase-out of Methyl Bromide in the U.S.," conducted by NCFAP, a Washington, D.C.-based think tank.

\section{References}

Carpenter J, Gianessi L, Lynch L. 2000. The Economic Impact of the Scheduled Phase-out of Methyl Bromide in the U.S. Washington, DC: National Center for Food and Agricultural Policy. $466 \mathrm{p}$. www.ncfap.org/

[CDPR] California Department of Pesticide Regulation. 1999a. Pesticide Use Report Data. www.cdpr.ca.gov/docs/pur/ purmain.htm

CDPR. 1999b. Suggested Permit Conditions for 1,3-Dichloropropene Pesticides. January 12. ENF 99-004.

Methyl Bromide Alternatives and Emissions Reductions Annual International Research Conference. 2000. www.epa.gov/ ozone $/ \mathrm{mbr} / \mathrm{mbrpro00}$.html

Montreal Protocol. 1992. The 1987 Montreal Protocol on Substances that Deplete the Ozone Layer. United Nations Environment Programme, Ozone Secretariat. www.unep.org/ozone/mont_t.shtml

Shaw DV, Larson KD. 1999. A metaanalysis of strawberry yield response to preplant soil fumigation with combinations of methyl bromide-chloropicrin and four alternative systems. Hort Science 34(5):839-45 